\title{
Making agile retrospectives more awesome
}

\author{
Adam Przybyłek, Dagmara Kotecka \\ Gdansk University of Technology, Faculty of Electronics, Telecommunications and Informatics \\ Narutowicza 11/12, 80-233 Gdansk, Poland \\ Email: adam.przybylek@gmail.com,dagkotecka@gmail.com
}

\begin{abstract}
According to the textbook [23], Scrum exists only in its entirety, where every component is essential to Scrum's success. However, in many organizational environments some of the components are omitted or modified in a way that is not aligned with the Scrum guidelines. Usually, such deviations result in missing the full benefits of Scrum [24]. Thereby, a Scrum process should be frequently inspected and any deviations should be corrected [23]. In this paper, we report on an Action Research project conducted in Intel Technology Poland to revise the work practices related to the Retrospective. During the focus group discussion in the company, retrospectives were generally judged ineffective because "the same things are discussed over and over". To cope with this challenge, we revitalized retrospectives by adopting collaborative games. The feedback received from three Scrum teams indicates that our approach improved participants' creativity, involvement, and communication, and produced better results than the standard retrospective.
\end{abstract}

\section{INTRODUCTION}

$\mathrm{O}$ VER the years agile methods have become extremely popular in the software industry. Among them, Scrum is the most adopted one [26]. Nevertheless, when examined more closely, by phrase "we are doing Scrum", organizations often mean, "we are using some parts of Scrum" [5, 6, 7]. Following the Scrum framework only partially or modifying it in a way that is not aligned with the principles of Scrum is commonly referred as ScrumBut [22]. Such misalignment almost always hides one or more inadequacies or dysfunctions which, if addressed and removed, would allow the company to take full advantage of Scrum [24]. In this paper, we focus on Scrum deviations related to the Sprint Retrospective.

Retrospective is a time-boxed meeting where the team inspects the past Sprint, learns from the experience and plans for improvements in the next Sprint. It should be held after the Sprint Review and prior to the next Sprint Planning [23]. During a retrospective meeting, the following questions should be answered [16, 21]:

- What worked well that we might forget to do in the next Sprint, if we do not discuss it?

- What did not work and how to do it differently next time?

- What did we learn?

Retrospectives address one of the principles of the Agile Manifesto [12]: "At regular intervals, the team reflects on how to become more effective, then tunes and adjusts its behavior accordingly". However, running an effective and enjoyable retrospective meeting is a challenge due to at least two factors: (1) Scrum does not prescribe techniques or best practices on how to do it; and (2) if this meeting is repeated in the same way over and over again, it becomes flat and may seem to be a waste of time.

In this work, we try to facilitate Sprint retrospectives by adopting collaborative games. Collaborative games refer to several structured techniques inspired by game play but designed for a purpose beyond pure entertainment, typically to develop a better understanding of a problem or to inspire new ideas about solving a problem. To keep participants focused on a specific purpose, collaborative games usually involve strong visual activities like drawing pictures, moving sticky notes, or assembling things. These activities challenge participants who are normally quiet or reserved to take a proactive role [14]. Furthermore, numerous studies have suggested that fun is a powerful tool in unleashing creativity $[13,19]$, and facilitating collaboration [10, 20, 25]. Our main interest in this research is to investigate whether the promised benefits of collaborative games are materialized during retrospectives.

The rest of the paper is structured as follows. The next section covers related work. Section III explains the research method and describes the research settings. Section IV reports the steps taken to carry out the research project. Section V presents and discusses the results. Finally, Section VI concludes the paper.

\section{RELATED WORK}

Although collaborative games are not new [1], their application to support software development processes has not received much attention yet. An important cornerstone for this research area were innovation games introduced by Hohmann [13] as market and product research techniques.

Trujillo et al. [25] adopted a game-based approach as a strategy to support the Inception phase of a project. They found that collaborative games increase stakeholders' involvement and improve collaboration between stakeholders and the development team. Gelperin [9] defined six collaborative games to facilitate requirements elicitation. He also defined a mapping system to help developers choose the best game to play. Ghanbari et al. [10] employed online collaborative games for gathering requirements from 
distributed software stakeholders. Their approach allowed less experienced individuals to identify a higher number of requirements.

Derby \& Larsen [4] presented the agenda with five type of games that could be used sequentially in the same retrospective meeting: set the stage, gather data, generate insights, decide what to do and close the retrospective. Gonçalves \& Linders [11] and Caroli \& Caetano [3] described respectively 13 and 44 games that can be used to facilitate retrospectives. Krivitsky [18] presented 16 games that can be combined in numerous retrospective agendas. He also provided the details to the games based on the team mood, size, proximity. Jovanović et al. [16] gathered retrospective games from various sources and established a new classification of games based on the four stage group development model proposed by Tuckman.

In our previous work [20], we proposed an extension to Open Kanban, which contains 12 collaborative games divided into four categories in compliance with four Open Kanban principles. This extension may help inexperienced teams better understand the principles of Kanban and support their teamwork.

To summarize, our work differs from $[9,10,25]$ in that we use collaborative games to stimulate developers while they used collaborative games to foster customers' engagement in the software development process. In turn, Derby \& Larsen [4], Gonçalves \& Linders [11], Caroli \& Caetano [3], Krivitsky [18], and Jovanović et al. [16] proposed catalogues of collaborative games that can be used to facilitate retrospectives, but they did not study how these games work in practice. Our study can be seen as a continuation of their work, since we evaluate some games from their catalogues. Finally, our previous work [20] concerned Kanban teams, while in the current work we support Scrum teams.

\section{RESEARCH METHOD}

Our study was conducted as Action Research [2]. Action Research is a partnership of the researchers with the study participants who use an iterative process to initiate improvement and study it. The researchers bring their knowledge of action research while the participants bring their practical knowledge and context. Action Research simultaneously assists in practical problem solving, expands scientific knowledge, and enhances participants competencies. A precondition for Action Research is to have a problem owner willing to collaborate to identify a problem, engage in an effort to solve it, analyze the results, and determine future actions [8]. The problem owner in this research was Intel Technology Poland. The company was interested in auditing its software development process and improving identified deficiencies. Three teams that participated in our research are characterised in Table I. These teams were coached by Grzegorz Reglinski who was one of the main Scrum Masters in the company. Grzegorz worked in close collaboration with us, acting as a coresearcher.

Action Research always involves two objectives: solving organizational issues and expanding scientific knowledge [2]. In this study, the practical objective was to revise the work practices related to the Retrospective, while the research objective was to explore how collaborative games may support the Retrospective.

TABLE I.

PARTICIPATING TEAMS

\begin{tabular}{|l|l|}
\hline \multicolumn{1}{|c|}{ Team } & \multicolumn{1}{c|}{ Description } \\
\hline $\begin{array}{l}\text { T1, } \\
\text { people }\end{array}$ & $\begin{array}{l}\text { The team had worked on the project for 18 months, when } \\
\text { we started our research. Team members had typically } 2 \\
\text { years of Scrum development experience. }\end{array}$ \\
\hline $\begin{array}{l}\text { T2, } \\
3 \text { people }\end{array}$ & $\begin{array}{l}\text { The team had just joined a new project, but all team } \\
\text { members had over 3 years of experience with Scrum. }\end{array}$ \\
\hline $\begin{array}{l}\text { T3, } \\
8 \text { people }\end{array}$ & $\begin{array}{l}\text { The team had worked on the project for } 7 \text { months. All team } \\
\text { members had over 3 years of experience with Scrum. }\end{array}$ \\
\hline
\end{tabular}

\section{ACTION RESEARCH IN INTEL TECHNOLOGY POLAND}

\section{A. Identification of ScrumButs}

We started by inspecting the Scrum process in a focus group. The aim was to investigate the practical implementation of Scrum and how it deviated from the textbook version. The focus group consisted of 12 professionals from the three teams. As shown in Table II, the participants had a range of experience. The discussion was structured around a set of 8 main questions and a few supplementary questions to each main question. However, herein, we only present questions and feedback related to retrospective meetings (all questions and feedback can be found in [17]). The questions were as follows:

- Which Scrum meetings do you find to be useful and which not?

- Why do you think so?

- Which Scrum meetings are you attending in your project?

- Which are you skipping?

- Why are you attending or skipping them?

TABLE II.

FOCUS GROUP CHARACTERISTICS

\begin{tabular}{|l|l|}
\hline \multicolumn{1}{|c|}{ Role } & \multicolumn{1}{c|}{ Experience in IT } \\
\hline Scrum Master & 10 years \\
\hline Product Owner & 2 years \\
\hline Design Lead & 10 years \\
\hline Senior Developer & 6 years \\
\hline Developer $x 7$ & $2-3$ years \\
\hline Developer Intern & 6 months \\
\hline
\end{tabular}

Only 3 out of 12 participants agreed on the importance of all Scrum meetings. They also believed that all Scrum elements must be implemented to effectively adopt the approach. A few others said that they attended all Scrum meetings just because the meetings had been already 
implemented at the company when they had joined. The majority perceived only Daily Scrum and Sprint Planning to be useful and they declared that if it had been up to them they would have attended only these two meetings. They also admitted that they did not fully understand Scrum and probably that was the reason why they did not see the point in attending other meetings. However, they were often forced to attend, which resulted in an aversion to the unwelcome duty. Finally, two participants hated Scrum and considered all Scrum ceremonies to be a waste of time.

The most unappreciated meeting was Sprint Retrospective. It turned out that some of the participants knew this meeting only in theory, but they had never experienced it in practice. On the other hand, the majority of those who experienced retrospectives considered them useless because no added value ideas came up. It was also noticed that usually a few team members did not actively participate in the meeting but were only listening. Nevertheless, one participant advocated the Retrospective as a way to improve the team and the development process.

Based on the feedback from the focus group, we concluded that the analyzed teams encountered common problems related to the Retrospective. Indeed, findings presented in the literature $[6,7,15,27]$ suggest that retrospectives are often judged ineffective and dropped because the same old things come up every time instead of insightful ideas.

\section{B. Selection of collaborative games}

We decided to freshen our retrospectives by leveraging collaborative games. After reviewing the available literature $[3,4,11,16]$, we came up with over 100 retrospective games. However, most of these games turned out to be complementary activities that can be run either to warm up the team and promote group interaction, or to help participants know more about each other and build the team. In turn, we were interested in games that directly focus on retrospective activities and allow participants to identify positives, negatives and learning. In addition, as advised by the Scrum Master, we tried to choose games that require participants to write things down on sticky notes before the discussion starts. The motivation for this recommendation was twofold. First, many people do not feel comfortable expressing their vulnerabilities verbally. Second, a few vocal people may dominate the discussion, while others, less vocal, prefer to blend in the background even though they have profound views on things. Taking into account the above, we analyzed the description of each game and chose the most suitable ones. At the end of the day, we had a set of 4 games, which we present below.

The Sailboat game [11] allows a team to think about their impediments, risks, good practices, and where they want to go. The game starts by drawing a sailboat, rocks, wind, and an island. The island represents the team's objectives/vision. The rocks represent the risks the team might encounter along the way. The anchor is everything that slows them down on their journey. The wind represent everything that helps them to reach their objectives. Next, participants write ideas on sticky notes and then post the ideas into the different areas according to the picture. Then, they discuss how to continue the practices that are written on the clouds/wind area, how to mitigate the identified risks, and what actions can be taken to fix the problems [20].

Mad/Sad/Glad [4] helps release a heavy emotional steam and gather data about feelings during the Sprint. Before the game starts the facilitator divides a board into three areas or hangs three posters labeled:

- Mad - frustrations, issues that have annoyed the team and/or have wasted a lot of time;

- Sad - disappointments, issues that have not worked out as well as was hoped;

- Glad - pleasures, issues that have made the team happy.

The game starts with everyone writing on sticky notes the issues that made the mad, glad or sad during the Sprint. When the timebox expires, participants post their sticky notes on/under the appropriate poster/area. Then, the team groups related sticky notes into logical themes. In the end, each theme is discussed, a consensus is found, and corrective actions are proposed.

The Starfish game [11] is an evolution of the typical retrospective questions. The game board comprises a circle divided into five equal areas:

- Stop Doing - activities or practices that have not brought value, or even worse, have been hindrances to progress;

- Less Of - activities or practices that have been done and have added value but have required more effort than really needed;

- Keep Doing - activities or practices that the team is doing well and wants to keep;

- More Of - activities or practices that are useful but not fully taken advantage of; and the team believes that they will bring more value if are done even more;

- Start Doing - activities or practices that the team wants to bring to the table.

To play the game, team members write their ideas on sticky notes, and then proceed in a manner analogous to that for Mad/Sad/Glad.

The 5Ls game [17] handles both the positive and negative aspects of the Sprint but also brings forth the continuous improvement. Before the game starts, the facilitator divides a board into five columns or hangs five posters labeled:

- $\quad$ Liked - what did the team really appreciate about the Sprint?

- $\quad$ Learned - what new things did the team learn during the Sprint?

- Lacked - what things could the team have done better in the Sprint?

- $\quad$ Longed For - what things did the team wish for but were not present during the Sprint? 
- Loathed - what things did the team dislike in the Sprint?

Again, the next steps are analogous to those of $\mathrm{Mad} / \mathrm{Sad} / \mathrm{Glad}$.

\section{Adoption of collaborative games}

We collaborated with the Scrum Master to properly adopt the games into the teams. Before a game was run for the first time, it was explained to the team. Table III shows an overview of the deployment process. The bottom entry in each cell indicates the game that was deployed, the top entry identifies the Sprint number when the deployment took place, while the time devoted to the retrospective session is presented in the middle. After each retrospective session, we used a questionnaire to collect feedback from the participants. Then, the results were analyzed and discussed with the team. In particular, we tried to track down the sources of both satisfying and dissatisfying experiences.

After two iterations, we reflected that our question set needed to be refined, since it did not captured all essential aspects of the conducted games (readers interested in the original questions and received feedback are referred to [17]). The work that had been done so far was considered as Phase I.

After revising the questions (the new question set is presented in Table IV), we started Phase II in which we followed the same research procedures as in Phase I. In the meantime, our preliminary results were appreciated by the senior management and we got a permission to coach a new team (T3) in adopting collaborative games. Unfortunately, we had to stop coaching team T1 after its 36th Sprint due to internal reorganization.

After the second implementation of $\mathrm{Mad} / \mathrm{Sad} / \mathrm{Glad}$, we reflected that this game did not have a potential to improve retrospective meetings, because it was too similar to the standard approach. Therefore, together with team T2, we attempted to enhance this game by adding two new categories, named "flowers" and "ideas". Flowers express appreciation to colleagues who have done something magnificent for the team or a particular team member. In turn, ideas are suggestions how to improve the teamwork or the process. We named the new version "Mood++". Figure 1 shows a photo of the whiteboard taken during the game.

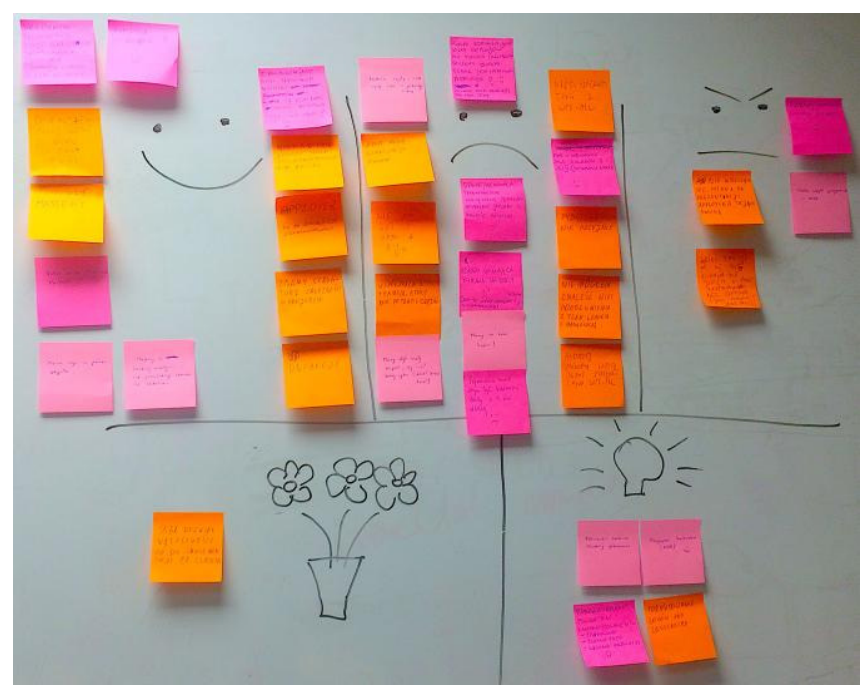

Figure 1. Mood++

\section{V.RESULTS}

Table IV summarizes the survey results. Participants reported their level of agreement or disagreement with each statement on a scale of 1 to 5, where 1 was "Strongly Disagree", 2 was "Somewhat Disagree", 3 was "Neither Agree nor Disagree", 4 was "Somewhat Agree", and 5 was "Strongly Agree". For each question, we first took the average per retrospective session, then based on these averages we took the average per team, and finally per game. All games except Mad/Sad/Glad were evaluated positively with respect to all categories. Even if they hardly scored above 3 for one category, they scored around 4 for other categories. They also generated very tangible output that was found to be valuable by most of the participants and the Scrum Master. Nevertheless, those who hated Scrum and perceived the meetings as a waste of time, also did not like our games.

TABLE III.

OVERVIEW OF THE DEPLOYMENT PROCESS (M/S/G = MAD/SAD/GLAD)

\begin{tabular}{|c|c|c|c|c|c|c|c|c|c|}
\hline & \multicolumn{2}{|c|}{ Phase I } & \multicolumn{7}{|c|}{ Phase II } \\
\hline Team T1 & $\begin{array}{l}31 \mathrm{st}, \\
90 \mathrm{~min}, \\
\text { Sailboat }\end{array}$ & $\begin{array}{l}32 \mathrm{nd}, \\
105 \text { min, } \\
\text { Starfish }\end{array}$ & $\begin{array}{l}33 \mathrm{rd}, \\
80 \mathrm{~min}, \\
\text { Sailboat }\end{array}$ & $\begin{array}{l}\text { 34th, } \\
\text { N/A }\end{array}$ & $\begin{array}{l}35 \text { th, } \\
70 \text { min, } \\
\text { Sailboat }\end{array}$ & $\begin{array}{l}36 \text { th, } \\
105 \text { min, } \\
\text { Starfish }\end{array}$ & N/A & N/A & N/A \\
\hline Team T2 & $\begin{array}{l}1 \mathrm{st}, \\
45 \mathrm{~min}, \\
\text { Sailboat }\end{array}$ & $\begin{array}{l}\text { 2nd, } \\
70 \text { min, } \\
\text { Starfish }\end{array}$ & $\begin{array}{l}3 \text { rd, } \\
45 \text { min, } \\
\text { Sailboat }\end{array}$ & $\begin{array}{l}4 \text { th, } \\
45 \text { min, } \\
\text { Starfish }\end{array}$ & $\begin{array}{l}5 \text { th, } \\
40 \text { min, } \\
\mathrm{M} / \mathrm{S} / \mathrm{G}\end{array}$ & $\begin{array}{l}6 \text { th, } \\
35 \text { min, } \\
\text { Mood++ }\end{array}$ & $\begin{array}{l}7 \text { th, } \\
55 \text { min, } \\
5 \mathrm{~L} \text { 's }\end{array}$ & $\begin{array}{l}8 \text { th, } \\
45 \text { min, } \\
5 \mathrm{~L} \text { 's }\end{array}$ & $\begin{array}{l}9 \text { th, } \\
55 \text { min, } \\
\text { Mood++ }\end{array}$ \\
\hline Team T3 & N/A & N/A & $\begin{array}{l}19 \text { th, } \\
50 \text { min, } \\
\text { Sailboat }\end{array}$ & $\begin{array}{l}20 \text { th, } \\
50 \mathrm{~min}, \\
\mathrm{M} / \mathrm{S} / \mathrm{G}\end{array}$ & $\begin{array}{l}21 \mathrm{st}, \\
70 \mathrm{~min}, \\
\text { Starfish }\end{array}$ & $\begin{array}{l}22 \mathrm{nd}, \\
50 \mathrm{~min}, \\
\text { Mood++ }\end{array}$ & $\begin{array}{l}23 \mathrm{rd}, \\
50 \mathrm{~min}, \\
\text { Sailboat }\end{array}$ & $\begin{array}{l}24 \text { th, } \\
50 \text { min, } \\
5 \text { L's }\end{array}$ & $\begin{array}{l}25 \text { th, } \\
80 \text { min, } \\
5 \text { L's }\end{array}$ \\
\hline
\end{tabular}


TABLE IV.

SUMMARY RESULTS

Rating scale:

1 - Strongly disagree, 2 - Disagree, 3 - Neutral, 4 - Agree, 5 - Strongly Agree

\begin{tabular}{|c|c|c|c|c|c|}
\hline The game: & ๓ొ & के & छे & $\sum$ & \\
\hline - produces better results than the standard approach & 4.0 & 4.0 & 3.0 & 3.7 & 4.0 \\
\hline - should be implemented permanently instead of the standard approach & 3.0 & 4.3 & 3.2 & 3.4 & 4.0 \\
\hline - may be considered as complementary to the standard approach & 3.5 & 3.6 & 4.2 & 4.0 & 4.2 \\
\hline - fosters participants' creativity & 3.3 & 3.7 & 3.7 & 3.9 & 4.0 \\
\hline - fosters participants' involvement & 3.8 & 4.1 & 3.2 & 3.9 & 4.4 \\
\hline - improves participants' communication & 3.5 & 3.1 & 2.3 & 3.7 & 4.2 \\
\hline - is easy to understand and play & 3.2 & 4.0 & 4.2 & 4.1 & 4.0 \\
\hline
\end{tabular}

\section{A. The sailboat game}

Although the participants agreed that Sailboat produces better results than the standard approach, they believed it should not be used too often due to three reasons. First, it would be boring to consider the vision and risks every time because they rarely change through the project. Second, using a sailboat as a metaphor for the team was too abstract for some participants, so the game was not perceived to be easy to play. Finally, the participants missed a good discussion on how to improve the teamwork and the process. On the other hand, they appreciated that the game fostered their involvement and created a friendly environment where they were able to express and discuss their frustrations in a constructive manner.

\section{B. The starfish game}

Starfish performed well in all categories except one (i.e. "communication among team members") that was not affected. Since the game covers all topics of classical retrospective and fosters participants' involvement at the same time, the participants advocated the substitution of the game for the standard approach. They also appreciated that the game helped them to understand each other perceived value on the way they worked.

\section{Mad/Sad/Glad and Mood++}

Although Mad/Sad/Glad was considered the easiest to understand and play, overall it performed the worst due to the reasons mentioned in Section IV-C. In particular, its impact on communication between team members was rated negatively. The reason for this was probably that the game is too simple and does not cover all topics that are usually addressed during a retrospective. Nevertheless, after enriching the game with two new categories, the communication aspect was significantly improved, while the new version performed overall as well as the Starfish game.

\section{The 5L's game}

Generally, 5L's received high marks in each category and outperformed all other games. When compared to Starfish and Mood++, it also covers all aspects of the Retrospective, but was considered superior especially in improving participants' communication. The other strong point of the game is that the participants' involvement was fostered. While playing this game, the participants even started to compete against one another to post the highest number of sticky notes.

\section{CONCLUSIONS}

This paper reports on an Action Research project in which we freshened retrospectives to be more engaging and insightful and to avoid monotony. In particular, we adopted five collaborative games and examined the ways in which these games could benefit retrospectives. The received feedback indicates that the adopted games improved participants' creativity, involvement, and communication. Besides, playing together created a type of glue that bonded a team together and made team members more comfortable to participate in the discussion.

We found out that there is no single collaborative game that would give the best result in all cases. Since the issues that a team deals with can be different in each Sprint and project, the Scrum Master should have a set of possible games to be able to pick the most effective one depending on the situation at hand. Moreover, playing the same game over and over would be boring. Furthermore, we observed differences in performance on particular aspects between the games.

The adopted games had proved so successful that not only did the participated teams continue to run them after the project finished, but they also spread their knowledge about the proposed approach and collaborative games started to be implemented in other teams that had not participated in the research. Accordingly, we believe that the usage of collaborative games in Agile Software Development is an 
emerging area of research, while our work represents only the beginning of the road. We thus call for further studies to examine other collaborative games and evaluate how collaborative games may support other Scrum ceremonies. We also hope that our research will inspire practitioners to adapt collaborative games and make their retrospective meetings more awesome.

\section{REFERENCES}

[1] Abt, C.C.: Serious Games. Viking Press, 1970

[2] Baskerville, R., Myers, M.D.: Special issue on action research in information systems: making IS research relevant to practiceforeword. In: MIS Quart 28(3), pp. 329-335, 2004

[3] Caroli, P., Caetano, T.: Fun Retrospectives - Activities and ideas for making agile retrospectives more engaging. Leanpub, 2016

[4] Derby, E., Larsen. D.: Agile Retrospectives: Making Good Teams Great. Pragmatic Programmers, 2006

[5] Diebold, P., Ostberg, J.-P., Wagner, S., Zendler, U.: What Do Practitioners Vary in Using Scrum? In: 16th International Conference on Agile Software Development (XP'15), Helsinki, Finland, 2015

[6] Drægert, A., Petersen, D.: ScrumBut in Professional Software Development. MSc thesis, Department of Computer Science, Aalborg University, 2016

[7] Eloranta, V., Koskimies, K., Mikkonen, T.: Exploring ScrumBut An empirical study of Scrum anti-patterns. In: Information and Software Technology Vol. 74, pp. 194-203, June 2016

[8] Easterbrook, S.M., Singer, J., Storey, M.A., Damian, D.: Selecting Empirical Methods for Software Engineering Research. In: Shull, F., Singer, J., Sjøberg, D. (eds.) Guide to Advanced Empirical Software Engineering, pp. 285-311, Springer, 2008, doi: 10.1007/978-184800-044-5_11

[9] Gelperin, D.: Increase Requirements Understanding by Playing Cooperative Games. In: INCOSE Inter. Symp., Denver, CO, 2011

[10] Ghanbari, H., Similä, J., Markkula, J.: Utilizing online serious games to facilitate distributed requirements elicitation. In: Journal of Systems and Softwar, vol. 109 (November 2015), pp. 32-49

[11] Gonçalves, L., Linders, B.: Getting Value out of Agile Retrospectives: A Toolbox of Retrospective Exercises. Leanpub, 2014
[12] Highsmith, J., Fowler, M.: The agile manifesto. In: Softw. Dev. Mag. 9, pp. 29-30, 2001

[13] Hohmann, L.: Innovation Games: Creating Breakthrough Products Through Collaborative Play. Addison-Wesley Professional, 2006

[14] International Institute of Business Analysis (IIBA): Agile Extension to the BABOK®Guide. Toronto, Canada, 2013

[15] Jeffries, R.: Fractional Scrum, or "Scrum-But". AgileAtlas, 2013

[16] Jovanović, M., Mesquida, A.L., Radaković, N., Mas, A.: Agile Retrospective Games for Different Team Development Phases. In: J. of Universal Computer Science, vol. 22(12), pp. 1489-1508, 2016

[17] Kotecka, D.: Enhancing Scrum with collaborative games. MSc thesis, Gdansk University of Technology, 2016

[18] Krivitsky, A.: Agile Retrospective Kickstarter. Leanpub, 2015

[19] Lin, L.-H., Lin, W.-H., Chen, C.-Y., Teng, Y.-F.: Playfulness and innovation - A multilevel study in individuals and organizations. In: 5th IEEE International Conference on Management of Innovation and Technology, Singapore, 2010

[20] Przybylek, A., Olszewski, M.: Adopting collaborative games into Open Kanban. In: 2016 Federated Conference on Computer Science and Information Systems (FedCSIS'16), Gdansk, Poland, 2016, doi: 10.15439/2016F509

[21] Ringstad, M.A., Dingsøyr, T., Brede Moe, N.: Agile Process Improvement: Diagnosis and Planning to Improve Teamwork. In: 18th European Conf. on Soft. Process Improv., Roskilde, Denmark, 2011

[22] Sutherland, J.: The ScrumButt Test: aka The Nokia Test. Available at https://www.scruminc.com/official-Scrumbutt-test-otherwise-known/, 2011

[23] Sutherland, J., Schwaber, K.: The Scrum Guide - The Definitive Guide to Scrum: The Rules of the Game. Scrum.Org and ScrumInc, 2016

[24] Schwaber, K.: Scrum is Hard and Disruptive. Available at http://www.verheulconsultants.nl/ScrumIsHardandDisruptive.pdf, 2006

[25] Trujillo, M.M., Oktaba, H., González, J.C.: Improving Software Projects Inception Phase Using Games: ActiveAction Workshop. In: 9th International Conference on Evaluation of Novel Approaches to Software Engineering (ENASE'14), Lisbon, Portugal, 2014

[26] VersionOne: 11th Annual State of Agile Survey. Tech. report, 2017

[27] Werewka, J., Spiechowicz, A.: Enterprise architecture approach to Scrum processes: sprint retrospective example. In: 2017 Federated Conference on Computer Science and Information Systems (FedCSIS'17), Prague, Czech Republic, 2017 